\title{
CURRÍCULO POR COMPETÊNCIA: ASCENSÃO DE UM NOVO PARADIGMA CURRICULAR
}

\author{
Antonio Chizzotti ${ }^{*}$
}

\begin{abstract}
RESUMO
$\mathrm{O}$ artigo analisa a ascensão de um novo paradigma normativo do currículo da educação básica em muitos sistemas nacionais de educação, tendo como referência as competências esperadas dos alunos ao fim da escolaridade. Apresenta o ingresso progressivo do conceito de competências promovido por agências e uniões internacionais e pelos países membros da Organização para a Cooperação e Desenvolvimento Econômico (OCDE) na formulação e gestão das políticas curriculares, indicando a centralidade do currículo escolar como foco nuclear para o enfrentamento dos desafios e exigências do desenvolvimento e da competitividade. Historia o compartilhamento dos debates dos diferentes sistemas de educação em torno da questão curricular e a formulação de um proposta consensual em favor das competências básicas esperadas dos alunos ao fim da escolaridade obrigatória nos respectivos sistemas de educação. A pesquisa apoia-se nos documentos produzidos e nas normas jurídicas promulgadas, que definiram as competências básicas para os países membros da OCDE para a educação obrigatória dos sistemas de educação dos países membros.
\end{abstract}

Palavras-chave: Competências. Educação básica. Sistema de educação. OCDE.

\begin{abstract}
The article examines the rise of a new normative paradigm of the basic education curriculum in many national education systems, with reference to the skills expected of students at the end of schooling. Display the join progressive concept promoted by international agencies and unions and the member countries of the Organization for Economic Cooperation and
\end{abstract}

\footnotetext{
* Doutor em Filosofia e História da Educação pela Pontifícia Universidade Católica de São Paulo (PUC - SP). Professor Aposentado da Universidade Federal de Uberlândia (UFU). Professor Associado do Programa de Pós-Graduação em Educação na Pontifícia Universidade Católica de São Paulo (PUC - SP).E-mail: anchizo@uol.com.br
} 
Development (OECD) in the formulation and management of curriculum policies, indicating the centrality of the school curriculum as a focus for the nuclear challenges facing the and requirements of development and competitiveness. Chronicle the debate sharing of different education systems around the curriculum issue and formulate a consensus proposal in favor of basic skills expected of students at the end of compulsory education in their respective education systems. The research is based on documents produced and enacted legal norms, which defined the basic skills to OECD member countries for the education mandatory education systems of member countries.

Keywords: Competency. Basic school. Education system. OECD.

\section{Introdução}

O artigo visa apresentar a ascensão do currículo por competência como um novo paradigma normativo do currículo escolar dos países que participam da Organização para a Cooperação e Desenvolvimento Econômico (OCDE). No campo das políticas públicas para a educação, os Estados passaram a intervir diretamente na organização do currículo, como estratégia para se posicionar na nova geopolítica do conhecimento, enfrentar o aguçamento da competitividade internacional, promover desenvolvimento econômico e a democratização do ensino, mobilizando o aparato do Estado para explicitar uma concepção e adotar um conceito convergente, comparativamente partilhado por outros Estados, como fundamento normativo para o currículo escolar. $\mathrm{O}$ termo competência ingressou na formulação das políticas curriculares dos sistemas de ensino, suscitou calorosas polêmicas e, ainda, provoca confrangedores debates.

O movimento que se desenvolveu, com incentivo de agências internacionais e de instâncias ministeriais de muitos países, convocou para o debate pesquisadores de diferentes áreas, políticos de diversas tendências, autores de diferentes origens. Foram muitos os afrontamentos teóricos, políticos e educacionais que envolveram a introdução das competências nos currículos escolares; alguns ainda persistem; outros evoluíram com a 
contribuição de pesquisadores de diferentes áreas e gestores de diversos sistemas de educação. Os currículos tornaram-se espelhos da complexidade social dos estados modernos. Um campo de estudo, antes asséptico e limitado a prescrições burocráticas ou restrito a especialistas, o "primo pobre da reflexão", segundo Forquin (2008, p. 7), abriu um amplo campo de investigação em torno da relação dinâmica entre o conhecimento e as estruturas escolares e sociais. Raulin (2008) avalia que os currículos, na terminologia francesa, designados como programas escolares, foram considerados, até então como questões imutáveis e apolíticas de competência exclusiva de peritos. No momento presente, as exigências feitas à escola, impuseram a necessidade de políticas educacionais para superar a fragmentação do currículo em disciplinas escolares autônomas e soberanas.

O texto procura revelar a lógica dos discursos oficiais que consagraram uma proposta, que se irradia por assimilações, imitações ou adoção explícita, como o novo paradigma normativo do currículo escolar da educação básica.

Muitos sistemas de ensino apoiam-se no todo ou em parte nas formulações políticas ou nas práticas curriculares definidas pelos países da OCDE, com conotações nacionais específicas. Ainda que se apresente como uma proposta soberana, são muitas as críticas e questões que provocam. O artigo reconhece que a par da ação dos Estados, a globalização abriu um amplo campo de pesquisas e estudos internacionais, partilhados e debatidos entre acadêmicos, além dos limites locais, regionais e nacionais sobre o conteúdo e práticas curriculares, reconhecendo a tendência cada vez mais internacionalizada e 'hibridizada' da questão curricular. Mas, não se pode ignorar que o currículo, como prática social pedagógica e educativa, é manifestação particular de prática sociopolítica. As reformas educacionais e curriculares, envoltas em racionalidades científicas, pressupostos epistemológicos e neutralidade axiológica, revelam consensos ideológicos, científicos e culturais, que legitimam a disputa pela hegemonia política. $\mathrm{O}$ currículo por competências é um tema revelador da confragosa disputa política e da vigorosa intervenção do Estado na reestruturação das relações capitalistas em um mundo globalizado e na legitimação política das forças que porfiam garantir a hegemonia cultural no mundo atual. 


\section{O novo paradigma normativo do currículo}

A despeito de todas as oscilações semânticas do termo, das muitas diatribes educacionais e políticas, que conflagraram as concepções curriculares no final do século passado e na primeira década do século atual, o conceito 'competência' ingressou, progressivamente, nos discursos sobre currículo. Promovido por agências e uniões internacionais, o termo firmou-se como novo paradigma curricular de muitos sistemas de educação. No percurso desse movimento, muitos autores, ideias, instituições foram mobilizados para alcançar alguns pontos convergentes que ingressaram decisivamente no mundo da educação. Parece oportuno levantar esse percurso e as grandes questões que agitaram os debates. Os principais temas convergentes desse paradigma tornaram-se referências amplamente utilizadas em muitos sistemas de educação e estão presentes nas agendas de educação, orientando as políticas educacionais de muitos países.

Em síntese, os currículos regidos pelas competências pretendem superar o currículo centrado na acumulação de conhecimentos formais, descontextualizados de qualquer ação, para um conceito em que se aprecia o resultado provocado pelos conhecimentos adquiridos, levando-se em conta as atividades nas quais esses conhecimentos se comprovam. Para Audigier e Tutiaux-Guillon (2008), são de transformações substantivas e aceleradas introduzidas nos sistemas de educação e de mudanças profundas nos objetivos e conteúdos curriculares, que renovaram os objetivos da escola para atender, eficazmente, às demandas e aos imperativos da sociedade e dos indivíduos. Para Legrande (2008), revela o propósito de aproximar os conhecimentos considerados pertinentes, tendo em conta aquelas situações em que o aluno precisa mobilizar tais conhecimentos em situações inéditas e imprevistas e, para Houchot e Robine (2007), de recolocar o processo de aprendizagem do aluno, até então, focado nos conteúdos de ensino e na difusa fragmentação das aprendizagens para um novo patamar voltado para o processo efetivo da aprendizagem. Os mais ufanistas consideram o currículo por competência um formidável movimento de renovação e mudança; outros, um instrumento útil para auxiliar nas atividades pedagógicas e auxílio oportuno para dar uma unidade consequente à fragmentação disciplinar. Enfim, um promissor caminho para o sucesso da 
educação escolar. Há, porém, contestações veementes que, com argumentos e avaliações diversas, convergem na crítica ao atrelamento do currículo às exigências do mercado.

\section{Pródromos de um novo paradigma}

Nos anos 1990, as políticas educacionais para os currículos da educação básica dos sistemas de ensino, sob o impacto da globalização e da montante da política econômica neoliberal, procuram, progressivamente, reformular os conteúdos e os métodos de ensino-aprendizagem, tendo, cada vez mais, como referência, as competências que todos os cidadãos devem adquirir no curso da escolaridade básica. Esse movimento derivou do processo de globalização e de suas consequências econômicas, políticas, sociais e culturais, que produziu, de um lado, uma ampla integração cooperativa internacional e, de outro, intensificou vigorosamente, a competitividade internacional pelo conhecimento e pela escolaridade da população. Um forte movimento de unificação de amplos espaços planetários e de uniformização cultural controlado pelo reforço regulador do Estado, paradoxalmente, provocando novas configurações identitárias das singularidades locais, redunda na urgência de reformar os currículos escolares.

A retomada das doutrinas neoliberais trouxe um novo vetor aos conceitos de Estado, à concepção de gestão e de finalidades da educação. A questão nodal da gestão deriva para a tendência, cada vez mais uniforme, de gerir o sistema de educação, imputando aos estabelecimentos de ensino a responsabilidade pelos resultados do sucesso do aluno. Para isso, foi criado um sistema uniforme de avaliação apoiado em indicadores quantitativos de resultados, que, por sua vez, também inclui a escola em um sistema de classificação comparativa e hierarquizada das instituições escolares. A responsabilização (accountability) torna-se o mote expressivo da gestão competente e profícua. As finalidades da educação inseremse no contexto competitivo interinstitucional e internacional, visando alcançar crescimento econômico dinâmico, coesão social estável e um posto eminente no sistema classificatório comparativo entre escolas ou entre sistemas escolares nacionais. $\mathrm{O}$ ranqueamento escolar e o lugar na 
classificação emergem como indicadores relevantes de qualidade da escola e do sistema de ensino.

Os estudos e pesquisas sobre a educação e os currículos escolares aportaram novas questões para os sistemas de educação: a descentralização operacional dos sistemas de ensino, a competição comparativa entre os sistemas de ensino e unidades escolares, as demandas sociais derivadas de transformações estruturais, os novos públicos escolares, a massificação e democratização do acesso ao ensino; no campo curricular, as críticas afirmaram a incapacidade das disciplinas responder aos novos referenciais epistemológicos sobre as finalidades educativas, a absolescência dos currículos escolares disciplinares, a urgência de elevação da qualidade da educação e os apelos pela democratização massiva dos currículos escolares.

A confluência dessas questões políticas e culturais mobilizou os sistemas de educação e pervadiu os currículos, a avaliação e os objetivos da educação e da formação. Novos conceitos ingressaram nos discursos sobre a educação e o currículo. O conceito competência tornou-se peremptoriamente a referência central das políticas públicas e das reformas curriculares, na primeira década do século atual.

\section{Introdução do termo e seu significado}

A noção de competência está, pois, no âmago das reformas curriculares contemporâneas; não é mero modismo volátil, pois, expressa muito mais que mera mudança lexical, é uma ruptura epistemológica, na perspectiva de Foucault (1966), uma episteme - a configuração específica que exprime e dá suporte a um novo discurso científico de uma época.

A adoção do conceito não foi pacífica: a polissemia do termo e sua ascensão como princípio normativo dos currículos educacionais provocaram confrontos conceituais e debates veementes. Envolveram políticos, pesquisadores, docentes e agências e instituições internacionais na busca de referências convergentes e na definição de um conceito. $\mathrm{O}$ objetivo foi superar as ambiguidades e discrepâncias e forjar uma definição partilhada para resolver a crise dos currículos escolares, contestados de muitas formas, pela sua distância das novas exigências científicas contemporâneas e pela inércia frente às demandas sociais. A ascensão e implantação do termo 
nas políticas curriculares adquiriram crescente visibilidade, conforme tendências internacionais confluentes e se consagraram como um novo paradigma na organização dos currículos de muitos países.

As competências, como base comum de conhecimentos a ser dispensada à população escolar, impuseram a interferência direta do Estado nos currículos escolares. Contraditoriamente, para alguns, significou a redenção de um sistema de ensino em processo falimentar. Tratar-se-ia de uma profunda reorganização nos currículos disciplinares centrados nas aquisições pontuais e sucessivas dos conteúdos de disciplinas isoladas, transladando para uma nova concepção que valoriza a aprendizagem mais individualizada, mantém maior coordenação transversal do ensino e garante um trabalho em equipe dos professores e de toda escola. Para outros, porém, críticos mais ácidos, as competências no currículo revelam um empenho de adaptação às exigências competitivas com a finalidade de formar uma elite para salvaguardar sua parte no mercado e manter um posto relevante nas classificações comparativas internacionais dos sistemas de educação.

A introdução oficial desse novo padrão curricular resulta de um movimento surgido no terceiro quartel do século passado. Foi provocado por grupos de estudos e pesquisas, de reuniões e congressos de agências internacionais e por recomendações propostas para os países membros da Organização de Cooperação e Desenvolvimento Econômico (OCDE) e a introdução nos sistemas nacionais europeus de educação. Nesse percurso, os estudos comparativos entre sistemas nacionais de ensino baseados no resultado obtido pelos alunos em língua materna, matemática e ciências, promovidos pela Associação Internacional de Avaliação Educacional (International Association for Educational Assessement - IEA), tiveram influência proeminente na aferição de resultados escolares.

A culminância desse processo derivou de um vigoroso debate sobre os fins da escola e dos conhecimentos disciplinares que se entrecruzaram por vias diretas ou cruzadas, tanto de autores e pesquisas quanto de países e agências, de uniões e blocos políticos. Os acordos e dissensos, as adesões e oposições, as consonâncias e conflitos, que agitaram o recesso da escola, não se confinaram aos foros escolares. Foram repercussões de questões sociais, políticas e culturais que convulsionaram a sociedade. 


\section{Reforma do sistema de ensino e do currículo}

As discussões sobre o currículo podem ser identificadas em períodos antecedentes distantes. Muitos trabalhos foram desenvolvidos pela Organização das Nações Unidas para a Educação, Ciência e Cultura (UNESCO), pelo Fundo das Nações Unidas para a Infância (UNICEF) e pelo Fundo Monetário Internacional (FMI). Apresentaram estudos e pesquisas, relatórios e sugestões para os sistemas de ensino permanecendo como proposições e sugestões que aprofundaram a reflexão e identificaram temas comuns e diferentes tendências e propostas. A composição abrangente dessas agências, sem poder de indução das políticas educacionais dos sistemas de ensino nacionais, relegou as recomendações ao arbítrio de cada país. O FMI teve maior poder de indução em países que recorreram a financiamento desse banco. Nesses casos, as condicionalidades do financiamento impuseram determinações explícitas a ser cumpridas, como o Brasil enquanto esteve vinculado aos financiamentos do Fundo. Em 1990, UNESCO, UNICEF, PNUD e Banco Mundial patrocinaram a Conferência Mundial sobre Educação para Todos, em Jomtien, Tailândia, reunindo representantes de governos, organismos e peritos internacionais para estabelecer um "Plano de Ação para Satisfazer as Necessidades Básicas de Aprendizagem", que pudesse ser uma referência e um guia para governos, organismos internacionais, instituições de cooperação bilateral, organizações não governamentais (ONG) e todos aqueles comprometidos com a meta da educação para todos. Na década de 1990, O Fórum Mundial de Jontien, na Tailândia em 1990, e a declaração da UNESCO Educação para Todos (UNESCO, 1990) resultante desse Fórum foram o mote de um ambicioso projeto para garantir um currículo básico para toda população mundial, que serviu de referência para as políticas de educação básica dos sistemas de educação. No ano 2000, o Fórum reafirmou, em Dakar, no Senegal, o compromisso de garantir o acesso gratuito à educação de qualidade para todas as crianças. As declarações atualizaram as discussões sobre a educação básica e foram um grande apelo político, seguido de manifestações oficiais enfáticas e de sugestões oportunas para a organização dos sistemas de educação. Os fóruns trouxeram recomendações relevantes: a afirmação da concepção ampliada de educação básica e necessidades 
educacionais básicas, a universalização do acesso, o foco na aprendizagem, entre outras, mas não feriram, direta e substantivamente, a questão da organização curricular.

Em 1996, um relatório da Comissão Internacional sobre Educação para o século XXI da UNESCO, presidida por Jacques Delors (1996) e outros catorze peritos, denominado Educação: um tesouro a descobrir, preconizava quatro pilares da educação para o novo século: aprender a conhecer, aprender a fazer, aprender a viver juntos e aprender a ser, porém esse relatório não propôs estratégias curriculares para a escola básica.

O ingresso da OCDE na formulação de um padrão curricular foi decisivo em virtude da dinâmica da organização e do foco privilegiado dessa organização: o desenvolvimento econômico - tema que afetou, profundamente, as economias nacionais engolfadas na globalização e sacudidas pela montante neoliberal.

Em 1987, sob a responsabilidade de Skilbeck (1990), o Centro de Pesquisa e Inovação Educacional (Center for Educational Research and Innovation - CERI) da OCDE elaborou, pela primeira vez, o estado da arte sobre a reforma dos currículos, apresentando a revisão sistemática e compreensiva dos principais problemas levantados pelos estados membros da OCDE sobre a questão curricular, com o propósito de estimular análises e resolver tensões às mudanças demográficas, econômicas e políticas experimentadas pelos países, na década 1980. O relatório faz um diagnóstico das transformações sociais e educacionais das décadas 1950 - 1980; assinala a mudança na compreensão do currículo da educação básica e avalia o processo para o desenvolvimento futuro dos currículos da educação primária e secundária. O relatório é, ao mesmo tempo, um diagnóstico das grandes questões levantadas aos currículos dos sistemas nacionais de educação e da centralidade da questão para afrontar as novas exigências do desenvolvimento dos países membros e revela.

o interesse crescente que suscita a adoção de um tronco comum de matérias fundamentais mostra que se está prestes, em diferentes países, de se encontrar um acordo sobre uma base comum de educação e sobre os aspectos prioritários dos currículos escolares (SKILBECK, 1990, p. 34). 


\section{As competências e a nova política curricular}

A definição da nova política curricular sobre as competências que todos os cidadãos devem adquirir para uma participação na sociedade ao longo da vida resultou, ao final de um percurso de debates, novas conceituações, redefinições ideológicas e políticas para contornar a polissemia do termo que se traduziram em um programa escolar para a educação básica para muitos países. O revigoramento da agenda neoliberal esteve no centro desse processo, ao introduzir novas lógicas nas relações entre a educação e o mercado, e provocou a emergência de um surto de internacionalização da educação superior e novos modos de privatização da educação escolar básica, em muitos países.

Não se deve tributar a crise curricular somente ao movimento de expansão mais recente da globalização; ela tem raízes mais remotas: nos estudos e pesquisas dos anos 1970, cresceram as críticas às desigualdades educacionais ocultas sob retórica da igualdade formal. Os países e as agências internacionais, por outro lado, já buscavam estabelecer uma relação mais dinâmica entre a educação e o desenvolvimento econômico.

Nessa perspectiva, não se deve ignorar as condições particulares do início do século redesenhando a geopolítica do capitalismo e do conhecimento e o incremento de uma literatura polêmica, polarizada nessas condições. Não se pode, porém, ignorar o movimento científico e social, que mudou o universo da educação escolar, no último quartel do século passado. Nos anos 1970, as críticas levantadas pelos movimentos contestadores estudantis provocaram querelas em torno da escolarização, seus fins, meios e limites. O currículo escolar foi, progressivamente, posto em questão por densa literatura crítica em diversas partes do mundo. Avolumaram-se as análises críticas ao currículo, ressaltando o caráter histórico e político da genealogia dos sistemas de educação, das disciplinas e dos conteúdos de ensino. Surgiram estudos revelando as relações entre a escola e a estratificação social; outros avaliaram as escolhas curriculares como produtos históricos de sociedades, de culturas e de valores nacionais; outros ainda analisaram o currículo oficial prescrito e o ensinado, o currículo visível e oculto, o conhecimento científico e o currículo escolar. Um tema, antes relativamente indene, surge conturbado por conflitos ideológicos e 
políticos, interesses sociais, disputas pelo poder, evidenciando seu caráter contingente e contraditório, produto histórico de lutas sociais. Basta evocar algumas dessas críticas levantadas pela sociologia crítica na França, por Bourdieu e seus discípulos, entre outros; pela 'Nova Sociologia' sobre o currículo e a cultura, na Inglaterra e pelas teorias críticas, nos Estados Unidos, entre muitas outras análises, que puseram o currículo no crivo de contendas ideológicas e litígios educacionais. A questão curricular, sob diferentes óticas e termos assemelhados, postos em evidência pela filosofia, história e sociologia do currículo, foi polarizando a urgência de um novo tipo de escolaridade básica. As questões econômicas, políticas e culturais afetaram os sistemas nacionais de educação e a gestão do aparato educativo. Levantaram questões sobre as finalidades emergentes da educação básica e incitaram a busca de respostas prementes aos modelos curriculares vigentes.

\section{OCDE e o projeto Definição e Seleção das Competências-Chave $(\mathrm{DeSeCo})^{1}$}

Em 1997, a OCDE incorporou o conceito para delinear o projeto de desenvolvimento econômico dos países membros. Para isso, tratou de dirimir as controvérsias e divergências em torno do conceito, a fim de desenvolver um enfoque colaborativo e multidisciplinar, e estabelecer o marco para as políticas educacionais dos países membros que acordassem definir o conjunto de competências-chave para os respectivos sistemas de educação. É relevante a influência anglo-saxônica na OCDE e nas questões educacionais, em um período de franca hegemonia do capitalismo angloamericano, e a exemplaridade que seus sistemas de educação representavam. Esses sistemas de educação, historicamente, guardam afinidade com o

\footnotetext{
1 Para citações, o texto usa a versão em inglês The Definition and Selection of Key competencies (DeSeCo). Executive summary. Organisation for Economic Co-operation and Development (OECD). O termo competências-chave tem diferentes designações nos sistemas de ensino: competências essenciais, em Portugal; compétences-clé, França; Schlüsselkomppetenzen, na Alemanha; key skills, na Inglaterra, País de Gales e Irlanda do Norte; core skills, na Escócia é especificada como básica, no Brasil, ou ainda, é nomeada como fundamental, mínima, entre outras.
} 
mercado e a formação profissional, e tendem a professar uma concepção pragmática da educação e encontrar a relevância instrumental dos currículos escolares. Essa exemplaridade teve influência significativa na OCDE, aproximando a tradição escolar universalista, republicana, da tradição liberal, pragmática e profissional da educação básica.

Entre 1997 a 2003, a OCDE patrocinou, sob a liderança da Suíça, a análise teórica e fundamentos conceituais sobre as competências-chave no contexto da OCDE (SALGANIK; RYCHEN; MOSER; KONSTANT, 1999) para dar suporte ao Projeto Definição e Seleção das Competênciaschave, conhecido como Projeto DeSeCo, 1997-2003. Para realizá-lo, reuniu um grupo de especialistas que trabalhou com políticos e educadores para fazer uma análise coerente e compartilhada sobre quais competênciaschave são esperadas dos jovens e adultos no mundo moderno e qual nível de competência devem alcançar com a escolaridade. O grupo tinha a finalidade de, em meio às diferenças ideológicas e conotações semânticas conflituosas, encontrar convergências e definir um marco conceitual e consensual sobre um termo para servir como fonte de informação para a identificação das competências-chave basilares e dar suporte às pesquisas comparativas internacionais que visam medir nível de competência de jovens e adultos, segundo Rychen e Salganik (2001, 2003). A elaboração do estado da arte sobre o conceito e a construção de um marco de referência comum concluiu com informe final em 2003, sobre as competências-chave para uma vida exitosa e um bom funcionamento da sociedade (RYCHEN; SALGANIK; MCLAUGHLIN, 2003). O projeto reconheceu a diversidade de valores e prioridades de países e culturas, e afirma que identificou também desafios universais da economia global e da cultura, assim como valores comuns que informam a seleção de competências mais importantes. Em resposta à questão: Quais são as competências necessárias para enfrentar os diversos desafios da vida?, o texto final do projeto DeSeCo responde que:

Definir essas competências pode melhorar a pertinência das avaliações concebidas para determinar em que medida os adolescentes e adultos estão preparados para afrontar as questões e exigências da vida e identificar os objetivos gerais da educação e da aprendizagem, ao longo da vida toda (OECD, 2005, p. 5). 
O elenco das competências deveria constituir os novos objetivos da educação, a rota para o desenvolvimento dos países e a orientação para a formação das novas gerações integrarem-se, coesivamente, na sociedade do conhecimento e no mundo do trabalho produtivo, considerando uma "abordagem inovadora baseada na noção de 'literacia' que remete à capacidade dos alunos de analisar, raciocinar e comunicar quando enunciam, resolvem e interpretam problemas dependentes de matérias diferentes" (OECD, 2005, p. 5).

O projeto teve papel importante na organização de debates internacionais e na sistematização de referências multinacionais para as políticas públicas de educação, tendo como suposto que os conhecimentos disciplinares são importantes, mas insuficientes para a complexidade crescente das atuais demandas sociais.

A definição dessas competências esteve conexa com a necessidade da Organização ter um marco explícito de referências para o Programa para a Avaliação Internacional de Estudantes (Programme for International Student Assessment - PISA, sigla em inglês). A busca de indicadores comparativos entre os sistemas de educação nacionais, promovidos pela OCDE, UNESCO e pelo EUROSTAT da Comissão Européia, irá incentivar a difusão de indicadores de performance do PISA para avaliar uma questão que se tornou tema dominante nos discursos educacionais: a qualidade da educação, como afirma Meunier (2005). A OCDE desempenhou papel preponderante na consolidação do PISA como um modelo de avaliação de desempenho baseado não mais em programas de ensino, mas em um conjunto de competências esperadas dos alunos da educação básica.

O objetivo do PISA consistia, e assim se consolidou nos anos subsequentes, em monitorar se os estudantes, ao final da escolaridade obrigatória, têm adquirido os conhecimentos e as habilidades necessárias em língua materna, matemática e ciências para sua plena participação na sociedade. No curso da elaboração desse marco conceitual, o grupo de especialistas identificou a diversidade das culturas escolares, os valores e as tradições dos diferentes sistemas de educação e as prioridades estabelecidas pelos diversos currículos nacionais. Frente às particularidades de cada sistema, os autores afirmam que procuraram encontrar valores comuns, as similaridades e identidades dos diferentes sistemas que propiciassem 
o desenvolvimento dos indivíduos e da sociedade e pudessem constituir os objetivos futuros da educação e das políticas educacionais dos estados membros, diante dos desafios da economia e cultura, cada vez mais globalizadas. A proposta da OCDE influenciou, direta ou indiretamente, os sistemas de educação de outros países, mesmo daqueles que não participam da Organização. O Brasil não é (ainda) membro da OCDE, mas partilha de alguns projetos, como o PISA, o Programa de Indicadores Mundiais da Educação (World Educational Indicators - WEI), o programa Panoramas da Educação (Education at a Glance) e o Inquérito Internacional sobre Ensino e Aprendizagem (Pesquisa TALIS) e, por meio do INEP, orientou a política de avaliações educacionais e inspirou avaliações do sistema de ensino (IDEB, ENEM, Prova e Provinha Brasil, SARESP entre outros).

$\mathrm{O}$ texto do projeto DeSeCo da OECD considera que:

Uma competência é mais que conhecimentos e habilidades. Envolve a capacidade de enfrentar demandas complexas, apoiando-se em e mobilizando recursos psicossociais (inclusive habilidades e atitudes) em um contexto particular. Por exemplo, habilidade de comunicar-se efetivamente é uma competência que se pode apoiar no conhecimento individual da linguagem, de habilidades práticas em tecnologia e informação, e em atitudes em relação às pessoas com as quais se comunica (OECD, DeSeCo, 2005, p. 4).

Assegura igualmente um fundamento para determinar quais as competências-chave, pois elas "não resultam de decisões arbitrárias sobre as qualidades e habilidades pessoais desejáveis, mas de considerações cuidadosas dos pré-requisitos psicossociais para a realização da vida e o bom funcionamento da sociedade" (OECD, 2005 p. 6).

A justificação da necessidade de estabelecer um conjunto pequeno de competências está apoiada no argumento de que:

A globalização e a modernização estão criando um mundo cada vez mais diverso e interconectado. Para compreender e interagir bem neste mundo, os indivíduos necessitam, por exemplo, dominar as tecnologias mutantes e compreender a enorme quantidade de informações 
disponíveis. Também enfrentam desafios coletivos enquanto sociedadetais como o balanço entre o crescimento econômico e a sustentabilidade ambiental e a prosperidade com a equidade social. Nestes contextos, as competências que os indivíduos necessitam adquirir para alcançar suas metas têm sido mais complexas, requerendo mais que o domínio de algumas habilidades bem definidas (OECD, 2005, p. 4).

À vista desses pressupostos, o Projeto propôs três categorias, compostas por três competências-chave cada uma, totalizando nove competências.

As três categorias pressupõem que os indivíduos dispõem de muitas ferramentas materiais, tecnológicas e socioculturais, que devem ser capazes de dominar, de se servir delas para interagir com os outros em um mundo interdependente e de agir, de modo autônomo e responsável, no seu contexto. As três categorias e as competências conexas são, segundo o projeto da OCDE (OECD, p. 10-15):

*categoria 1: Usar ferramentas interativamente - as demandas sociais e profissionais da economia global da sociedade da informação pressupõem ferramentas socioculturais, para o aluno manter-se, tecnologicamente, atualizado e adaptar os meios às suas necessidades e, assim, dialogar ativamente com o mundo. Isso supõe que tenha competências para:

a) usar a linguagem, os símbolos e os textos de modo interativo;

b) usar o conhecimento e a informação de maneira interativa e

c) utilizar as tecnologias de modo interativo.

*categoria 2: Interagir com grupos heterogêneos - os seres humanos dependem de suas interações com os outros, seja para sua sobrevivência material e psicológica seja para sua identidade social, e, assim, construir relações interpessoais saudáveis e novas formas de cooperação. Face à diversidade nas sociedades pluralistas, à importância da empatia e do capital social, os indivíduos devem ter competência para:

a) relacionar-se bem com os outros;

b) cooperar e saber trabalhar em equipe e

c) saber gerir e resolver conflitos. 
*categoria 3: Agir de modo autônomo - agir autonomamente requer a compreensão do ambiente circunstante, das dinâmicas sociais, das funções que cada um desempenha, ou quer desempenhar, gerindo sua vida de modo reflexivo e responsável, com controle de suas condições de vida e de trabalho. Assim, para manter sua identidade e realizar seus objetivos em um mundo complexo, para saber exercitar seus direitos e assumir suas responsabilidades e para compreender seu meio e seu modo de funcionamento, precisa ter competência para:

a) saber compreender, agir e decidir em um contexto social amplo;

b) ser capaz de organizar e realizar seus projetos de vida e metas pessoais e

c) defender e assegurar seus direitos, interesses e limites e suas necessidades.

O projeto preconiza usar a experiência do PISA para mensurar as competências adquiridas pelos adolescentes e adultos, para enfrentar os desafios da vida e comparar os resultados da aprendizagem das diversas culturas nacionais.

O texto explicita que competência implica a "capacidade de, usando os conhecimentos e a experiência adquirida, agir com eficácia, em um determinado contexto ou em situações complexas, ou diversas $[\ldots]^{\prime}$ 'competência' entende-se aqui um conjunto de conhecimentos, saberes, disposições e valores" (OECD, 2005, p. 6).

A proposição do conceito de competências-chave do projeto DeSeCo insiste em algumas questões: o conceito de competência está correlacionado à noção de educação permanente, não se restringindo à educação escolar e, consequentemente, compreendendo, mas, também, ultrapassando a restrição do conceito dos currículos confinados em disciplinas estanques. $\mathrm{O}$ conceito não se limita à habilidade de dominar uma técnica particular, mas o termo exprime uma prática que envolve aptidões cognitivas, atitudes e outras disposições. Ele "implica também a capacidade de responder às exigências complexas e pode mobilizar e explorar os recursos psicossociais - habilidades e atitudes em um contexto particular" (OECD, 2005, p. 6). 
Cada uma das competências-chave é concebida como a síntese de conhecimentos fundamentais indispensáveis em razão da diversificação do conhecimento humano, síntese conexa com a capacidade de execução em situações variadas e da adoção de atitudes, tais como o respeito de si e do outro, a solidariedade, a criatividade e a participação. A adoção de um programa curricular multinacional comum convulsionou tradições curriculares nacionais de muitos países. Apesar de contestações e divergências residuais, convergiu para um amplo conjunto de proposições, produzido por fóruns e grupos de trabalho, que se consolidou na proposta das competências básicas indispensáveis que todo aluno deve adquirir ao final da escolaridade obrigatória.

\section{Considerações finais}

Competência é um conceito central nas propostas da OCDE em torno do qual a Organização tem elaborado propostas para estimular o emprego e o crescimento econômico, a inserção e reinserção no mercado de trabalho, sobretudo, nessa fase de crise econômica e financeira caracterizada por elevada taxa de desemprego em muitos países. O conceito tem ampla circulação nos programas de formação profissional nos quais a preparação técnica para o emprego oferece conhecimento e práticas operacionais para o exercício de um posto de trabalho. Documentos recentes da OCDE têm sido elaborados para atender as novas demandas de formação para um mercado assolado pela crise financeira de 2008 e pelo acirramento da competitividade internacional.

O Relatório de trabalho sobre as habilidades e competências para o novo milênio para os alunos dos países da OCDE (OECD, 2010) é enfático na reafirmação da urgência em promover as habilidades funcionais em Tecnologias da Informação e Comunicação (TIC) a fim de alcançar as competências necessárias para aplicá-las no âmbito dessas tecnologias no novo milênio.

Em 2011, a OCDE elaborou uma estratégia para o incremento das competências (OCDE, 2011). O documento considera a questão das competências como tema crucial na atual fase de desemprego gerada pela crise e concorrência crescente, e a elaboração de estratégias é parte do 
esforço global da OCDE para facilitar a retomada econômica, o emprego e o crescimento. Considera que as políticas de competências melhoraram o nível de educação, entretanto, persistem problemáticas importantes que induzem integrar os trabalhos da Organização, já existentes sobre a questão, e orientar os países nas diferentes etapas do processo de elaboração das políticas em favor das competências. O documento promete, para o começo de 2013, em preparação a publicações regulares sobre as Perspectivas das Competências (Skills Outlook), baseadas nas fontes de dados da OCDE, a elaboração de uma estratégia completa sobre as performances, fixando os princípios que deverão orientar as políticas nacionais sobre as competências. Promete também criar, à semelhança do Programa Internacional de Avaliação do Estudante - PISA, o Programa para Avaliação Internacional das Competências dos Adultos (Programme for the International Assessment of Adult Competencies - PIAAC) e o programa de Avaliação do Resultado da Aprendizagem do Ensino Superior (Assessment of Higher Education Learning Outcomes - AHELO). Esses programas vão compilar e analisar os dados a fim de mensurar o valor das competências específicas e sua em relação com o emprego. É previsível que esses modelos avaliativos venham a ter, em futuro próximo, a mesma difusão e influência que o PISA tem na avaliação atual dos resultados do aprendizado dos alunos da educação básica.

O projeto da OCDE difundiu-se pelos países membros, no oriente e ocidente. Como proposta, muitos sistemas nacionais de educação adotaram, adaptando-o às condições específicas das respectivas tradições históricas e sociais do seu sistema educacional, com resultados muito variáveis. A União Europeia apropriou-se dos temas e debates promovidos pela OCDE e organizou um 'marco de referência europeu' para o currículo da educação ao longo da vida. Com a expansão dos 'sistemas de ensino' privados que se habilitam, por meio de convênios, a gerir o todo ou a parte dos sistemas municipais de ensino, as propostas curriculares desses sistemas respaldamse nos projetos da OCDE, adaptando-as ao currículo nacional.

$\mathrm{O}$ projeto da OCDE tende a centrar a educação na perspectiva pragmática, orientada para a formação profissional e centrada na performance individual do aluno. O currículo, voltado para as competências que o aluno deve alcançar, procura atender à nova configuração da produção 
capitalista e à nova conjuntura da formação do trabalhador: exigir maior grau de escolaridade, desempenho escolar mais elevado, melhor nível de conhecimentos e comunicabilidade, eficiência polivalente, flexibilidade versátil, iniciativa criadora e responsabilidade - um conjunto de habilidades e atitudes que o torne mais competente no processo produtivo e mais competitivo na hierarquia ocupacional. $\mathrm{O}$ tom eminentemente econômico dos projetos da OCDE tem ampla aceitação nos setores que toma a educação e a formação como bem e serviço mercantis, sujeitos às leis de mercado, ou eufemisticamente, quase-mercado. São aptos para a formação profissional ou para as propostas de ensino integrado entre a formação básica e a formação profissional. Há, porém, veementes contestações às orientações curriculares difundidas pela OCDE, em virtude do viés instrumental da educação e voltado para o mercado de trabalho, desconsiderando ou, ao menos, preterindo a formação para uma cultura comum.

\section{Referências}

AUDIGIER, François; CRAHAY, Marcel; DOLZ, Joaquim; DELHAXHE, Arlete. Curriculum, enseigment et pilotage. Bruxelles: De Boek, 2006. AUDIGIER, François; TUTIAUX-GUILLON, Nicole (Dir.). Compétences et contenus: les curriculum en question. Bruxelles: De Boeck, 2008. p. 27-50. AUDIGIER, François; TUTIAUX-GUILLON, Nicole. Compétence et contenus. Les curriculum em question. Bruxelles: De Boeck, 2008.

CLARK, Linda; WINCH, Christopher. A European skills framework? but what are skills? Anglo-Saxon versus German concepts. Journal of Education and Work, London, v. 19, n. 3, jul. 2006. p. 255-269.

FORQUIN Jean-Claude. Sociologie $d u$ curriculum. Rennes: Presses universitaires de Rennes, 2008.

GAUTHIER, Roger-François. Les contenu de l'enseignement secondaire dans le monde: état des lieux et choix stratégiques. Paris, UNESCO, 2006. HOUCHOT, Alain; ROBINE Florence. Les livrets de competénces: nouveaux outils pour l'évaluation des acquis. . (Org.). Rapport de l'instruction générale de l'éducation nationale. França: IGEN; Ministério da Educação Nacional, 2010. 
LEGENDRE, Marie-Françoise. La notion de competence au coeur des réformes curriculaires; effect de mode ou moteur de changements en profounder. In: MEUNIER, Olivier. Standards, compétences de base et socle commun. Les dossiers de La VST, 2005. Disponível em:<www.inrp. fr.f/vst/Dossiers/Standards/ sommaire.htm>. Acesso em: 20 Set. 2011.

OCDE. École e qualité, Paris: OCDE, 1989.

OECD. Skills Strategy. OECD, 2011.

. The Definition and Selection of key Competencies. Executive summary. Disponível em: <www.oecd.org/edu/statistics/deseco>. Acesso: 12 Set. 2011.

. Working paper 21st Century skills and competencies for new millennium for learners in OECD countries. n 41. Disponível em: $<$ http. www.ite.edicacion.es>. Acesso em: 20 Out. 2011.

RAULIN, Dominique. Les programmes scolaires: Des disciplines souveraines au socle commun. Bruxelles: De Boeck, 2008.

RYCHEN D.S.; SALGANIK L.H. (Eds.). Defining and selecting key competencies. OCDE, 2001.

RYCHEN D.S.; SALGANIK L.H. (Ed.). Key competencies for a successful life and a well-functioning society. OECD, 2003.

SALGANIK, L. H.; RYCHEN, D. S.; MOSER, U.; KONSTANT, J. Projects on competencies in the OECD context: Analysis of theoretical and conceptual foundations, OECD, 1999.

SKILBECK, Malcolm. La réforme des programmes scolaires. Où en sommes nous? OCDE. Centre pour la Recherche et l'Innovation dans l'Enseignement (CERI). OCDE: Paris, 1990.

UNESCO. Declaração Mundial sobre Educação para Todos (i) e Plano de ação para satisfazer as necessidades básicas de Aprendizagem (II) In: TORRES, Rosa Maria. Educação para todos; a tarefa por fazer. Tradução de Daisy Vaz de Moraes. Porto Alegre: Artmed, 2001.

Data de registro: $20 / 12 / 2011$

Data de aceite: $21 / 03 / 2012$ 